Review

\title{
Ring Expansion of Vinylaziridines through the Strain-Release Pericyclic Reaction: Recent Developments and Applications
}

\author{
Yu Mi Heo and Seung-Mann Paek * \\ College of Pharmacy and Research Institute of Pharmaceutical Sciences, \\ Gyeongsang National University, Jinju daero, Jinju, Gyeongnam 660-751, Korea; \\ E-Mail: ymh@gnu.ac.kr \\ * Author to whom correspondence should be addressed; E-Mail: million@gnu.ac.kr; \\ Tel.: +82-55-772-2424; Fax: +82-55-772-2429.
}

Received: 23 July 2013; in revised form: 1 August 2013 / Accepted: 7 August 2013 /

Published: 12 August 2013

\begin{abstract}
Recent syntheses of azetidines, pyrrolidines, piperidines and azepines through cycloaddition or sigmatropic rearrangements of vinylaziridines are described. Applications to natural product synthesis and mechanistic investigations are also summarized.
\end{abstract}

Keywords: vinylaziridines; cycloaddition; rearrangement; ring expansion

\section{Introduction}

Vinylaziridines, which simultaneously possesses electrophilic and nucleophilic centers in their structure, have been regarded as highly valuable synthetic intermediates because of their unique reactivity toward various other reactive species such as activated alkenes, heteroatoms and metallic species [1]. Since the expansion of a vinylaziridine via sigmatropic rearrangement was first ring reported in 1967 [2,3], a variety of these transformations have been shown to offer efficient and valuable synthetic routes to a wide variety of products. Nowadays the vinylaziridine moiety plays an important role in the preparation of 4-, 5-, 6- and 7-membered azacycles according to the selection of reagents and reaction conditions (Scheme 1). Because this transformation releases the severe ring strain of the aziridine ring, this conversion usually proceeds in a highly efficient manner. In light of this unique reactivity and effectiveness, a lot of synthetic research in this area is being carried out even now. In this review recent developments and application of these methodologies in the last decade are summarized. 
Scheme 1. Synthetic applications of the vinylaziridine moiety.

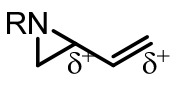

vinylaziridine

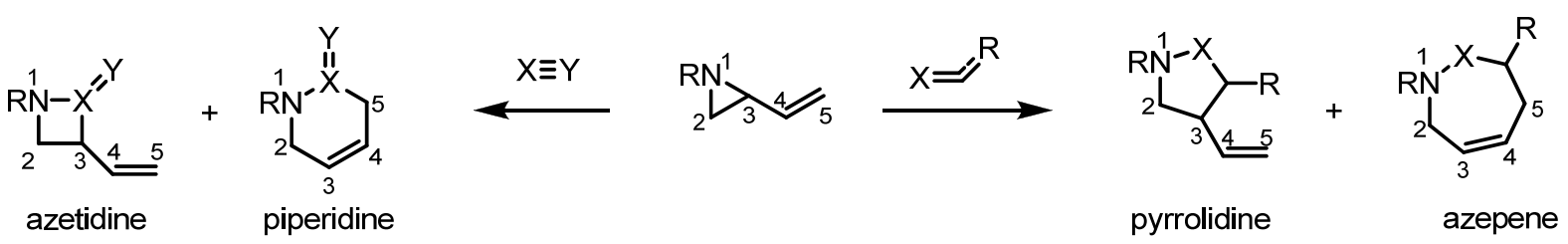

\section{Results and Discussion}

\subsection{Azetidines from Vinylaziridines}

Synthesis of a $\beta$-lactam from a vinylaziridine through insertion of carbon monoxide was published in 1993 (Equation 1 in Scheme 2) [4]. This enabled the preparation of the $\beta$-lactam antibiotic PS-5 and initiated studies into related transformations. In the early 2000s, however, a silyl-substituted vinylaziridine was converted into a 6-membered azacycle under similar reaction conditions (Equation 2 in Scheme 2) [5].

Scheme 2. Synthesis of $\beta$ and $\delta$-lactams from the vinylaziridine.
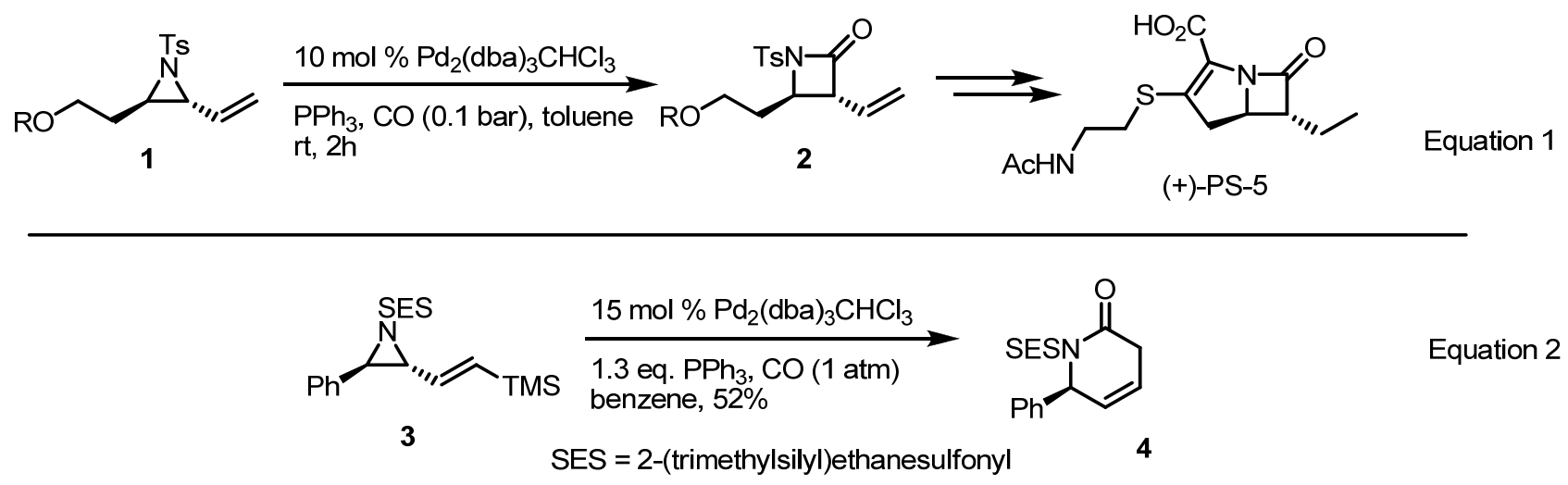

A recent report from the Aggarwal group at Bristol University suggests a plausible explanation of this discrepancy (Scheme 3) on the basis of a Pd-mediated isomerization and $\mathrm{CO}$ insertion mechanism [6]. Once $\mathrm{CO}$ is inserted into the carbon, the so-formed $\pi$-allyl complex 6 is dominantly and quickly converted to $\beta$-lactam 8 (Equation 3 in Scheme 3), but when the substituent is a silyl group, carbonylation occurs at the carbon adjacent to silicon because of the shorter C-Pd bond length [7]. Once $\operatorname{Pd}(0)$ is inserted into the carbon adjacent to silicon, it affords cyclization product 11 after protodesilylation (Equation 4 in Scheme 3). Based on this explanation and hypothesis, various reaction conditions were surveyed to control the regioselectivity of this conversion, as shown in Equation 5 in Scheme 3. 
Scheme 3. Mechanism of $\beta$ and $\delta$-lactam formation from vinylaziridines.

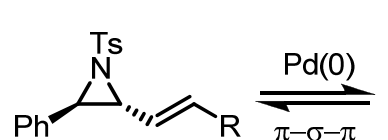

5

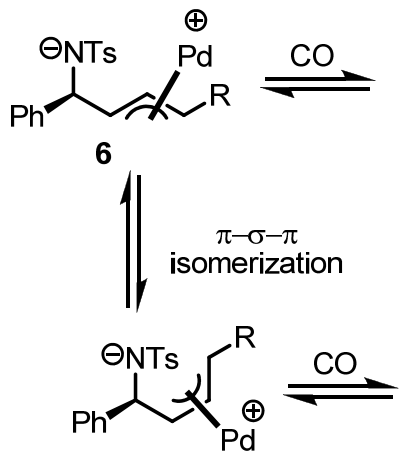

9<smiles>[R]C=CC(C([R6])=O)C([PH2+])[N+]([NH3+])([O-])c1ccccc1</smiles>

$7 \mathrm{R}=$ aryl<smiles>[GeH3][C@@H]1[CH]CC1</smiles><smiles>C1CCC1</smiles><smiles>[R]C=C[C@H]1C(=O)N([AlH2])[C@@H]1[PbH]</smiles>

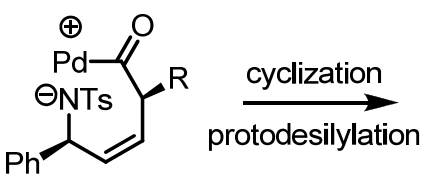

$10 \mathrm{R}=\mathrm{TMS}$<smiles>O=C1CC=C[C@H](c2ccccc2)[AlH2]1</smiles>

11

Equation 4

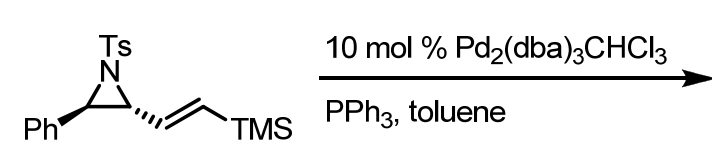

12<smiles></smiles>

13

CO (50 bar), $43 \%$

CO (0.1 bar), -<smiles>O=C1CC=CC([Al])[NH+]1[Te]</smiles>

11

$20 \%$

$61 \%$

\subsection{Pyrrolidines from Vinylaziridines}

Most recent pyrrolidine syntheses from vinylaziridines apply transition metal catalysts, especially $\operatorname{Pd}(0)$ species, with an activated $\pi$-bond as shown in Scheme 4 . In the presence of the metal catalyst the nucleophilic nitrogen and electrophilic $\mathrm{C} 3$ cyclize with the activated $\pi$-bond in a stereoselective manner.

Scheme 4. Synthesis of 5-membered azacycles from vinylaziridines.
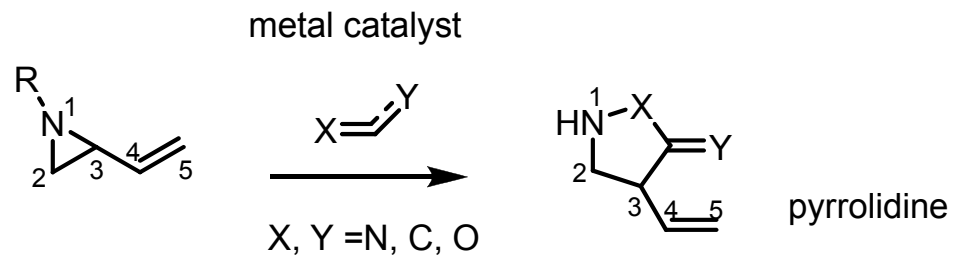

For example, the Alper group reported in 2000 a highly efficient synthetic protocol for preparing 5-membered urea skeletons 16 using $\mathrm{Pd}(\mathrm{OAc})_{2}, \mathrm{PPh}_{3}$ and aryl isocyanates (Scheme 5). Instead of isocyanate, carbodiimide or thioisocyanate could also be used to give the corresponding azacycles $\mathbf{1 8}$ or 19, respectively in good yield [8]. Because this versatile transformation needed phosphine ligands for the catalytic cycle, it offered the possibility of using chiral ligands to control the enantioselectivity of these reactions.

In fact, the Trost group has published a chiral version of this transformation employing the Trost ligand 22 (Scheme 6) [9]. Cycloaddition of benzyl, vinylaziridine $\mathbf{2 0}$ and benzyl isocyanate $\mathbf{2 1}$ with catalysis by $\operatorname{Pd}(0)$ and a chiral phosphine ligand produced the chiral cyclic urea $\mathbf{2 3}$ in a highly efficient and enantioselective manner. 
Scheme 5. Synthesis of 5-membered cyclic ureas from vinylaziridines.
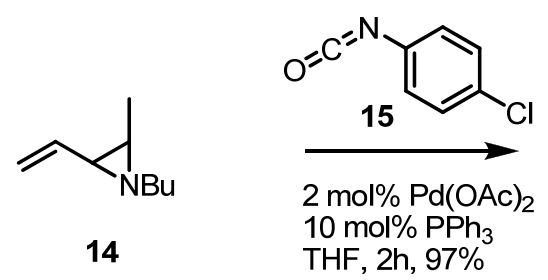<smiles>C=CC1C(C)NC(=O)N1c1ccc(Cl)cc1</smiles>

2:1 cis/trans mixture
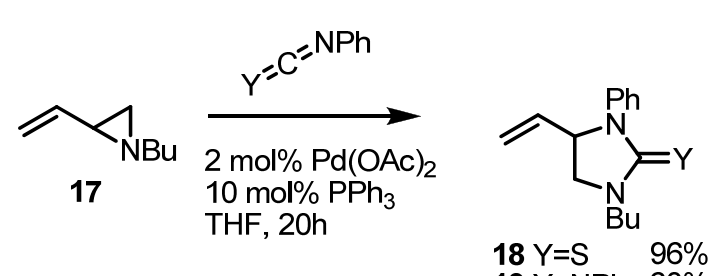

$19 \mathrm{Y}=\mathrm{NPh} \quad 60 \%$

This reaction could be applied to other aromatic or benzylic aziridines and isocyanates with similar results. This result is a good example of how strain-release cycloaddition can be applied to enantioselective catalysis.

Scheme 6. Enantioselective synthesis of cyclic ureas from vinylaziridines.

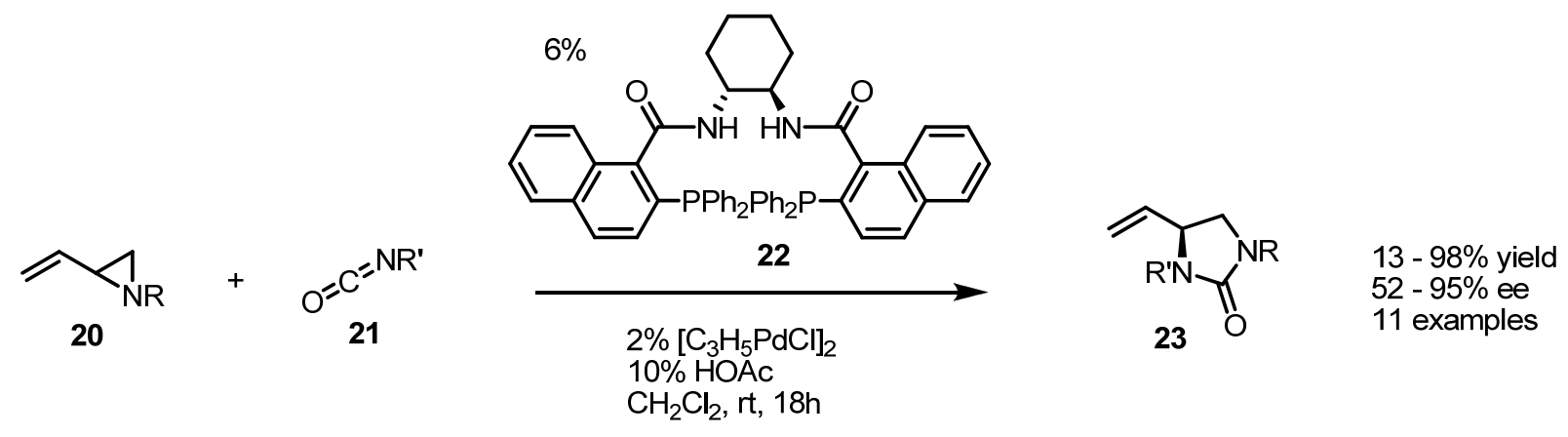

Instead of isocyanate, $\mathrm{CO}_{2}$ could be utilized as a $\pi$-bond partner. The Aggarwal group reported an application of this transformation with $\mathrm{CO}_{2}$ to form substituted oxazolidinones [10] (Scheme 7). When aryl vinylaziridine 24 was treated with $\mathrm{Pd}(0), \mathrm{PPh}_{3}, \mathrm{CO}_{2}$ and a quaternary ammonium salt, the desired oxazolidinone 25 was obtained in high yield. This transformation could be performed with various substrates without loss of chirality. Noticeable is the fact that simple $\mathrm{CO}_{2}$, although nonpolar, could be incorporated in this bond formation. The electrophilicity of the $\mathrm{CO}_{2}$ carbon atom is thought to play an important role in the reaction outcome.

Scheme 7. Formation of oxazolidinones from vinylaziridines.<smiles>[R]C=C1[CH-][C@@H]1[R]</smiles>

24

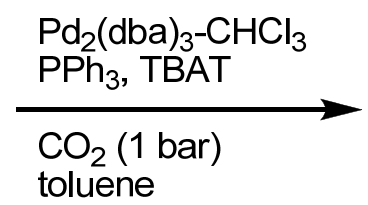

TBAT= tetrabutylammonium difluorotriphenylsilicate

An alkene can be used in this transformation as a $\pi$-bond partner if it is activated with other substituents. The Yamamoto group demosntrated this type of conversion in 2002 [11]. As shown in Scheme 8 , trisubstituted alkene $\mathbf{2 7}$ is highly electron deficient because of its two sulfonyl groups. This highly activated $\pi$-bond reacted with simple vinylaziridine to produce pyrrolidine $\mathbf{2 8}$ in almost 
quantitative yield, although with low stereoselectivity. This reaction could be applied to other similar substrates in over $69 \%$ yield.

Scheme 8. Formation of pyrrolidines from a vinylaziridine and an activated alkene.

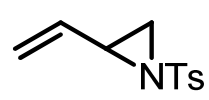

26

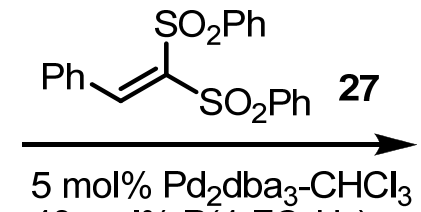

$40 \mathrm{~mol} \% \mathrm{P}\left(4-\mathrm{FC}_{6} \mathrm{H}_{4}\right)_{3}$

THF, rt, $99 \%$<smiles>C=CC1CN([13CH3])C(c2ccccc2)C1(S(=O)(=O)O)S(=O)(=O)c1ccccc1</smiles>

55:45 cis/trans mixture

Improvement for this type of reaction was recently achieved by the Aggarwal group [12]. To expand the synthetic applications, methyl vinyl ketone (MVK) was utilized as a Michael acceptor. This replacement of disulfonyl alkene 27 with MVK afforded a general stereoselective route to the pyrrolidine skeleton. This transformation wase utilized successfully in a total synthesis of kainic acid (Scheme 9). This beautiful example shows that the strain-release cycloaddition of vinylaziridines can be applied to synthesize complex natural products.

Scheme 9. Total synthesis of (-)-kainic acid.<smiles></smiles>

29

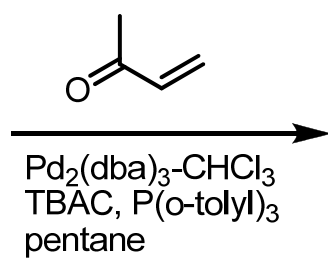

pentane<smiles>CC(=O)[C@H]1CN(C)C(c2ccccc2)[C@@H]1/C=C/c1ccccc1</smiles>

30<smiles>C=CCCCCCCC(=C)C</smiles>

(-)-kainic acid

$62 \% 10: 1 d r$

Like alkenes, electron deficient alkynes also can be utilized in this cycloaddition. Thus the highly electron deficient alkyne 32 was applied to obtain the highly strained [3.2.0] bicyclic diester 34 [13] (Scheme 10). This transformation could be carried out without any metal catalyst because of the intrinsic electrophilicity of alkyne 32, like in the case of $\mathrm{CO}_{2}$. The seven-membered azacycle $\mathbf{3 3}$ was suggested as a plausible intermediate.

Scheme 10. Preparation of bicyclic pyrrolines.

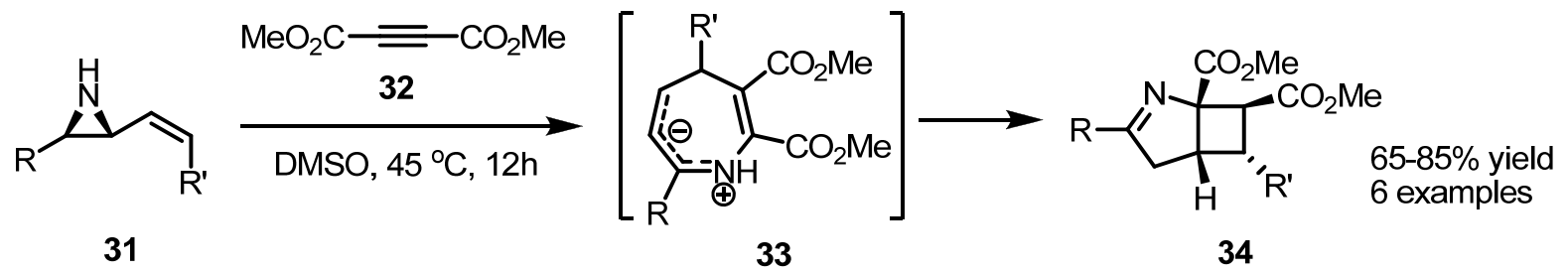

Instead of Pd (0) species, a copper catalyst was found to be useful in an isomerization of vinylaziridines. Njardarson and coworkers reported that the synthesis of substituted pyrrolidines $\mathbf{3 7 ,} 39$ can be achieved with copper species catalysis and anhydrous hexafluoroacetylacetonate ligand [14]. 
This reaction is expected to proceed via a 1,3-rearrangement mechanism [15]. This conversion is also applicable to variously substituted vinylaziridines, as shown in Scheme 11 [16].

Scheme 11. Copper catalysis of a [1.3]-rearrangement.
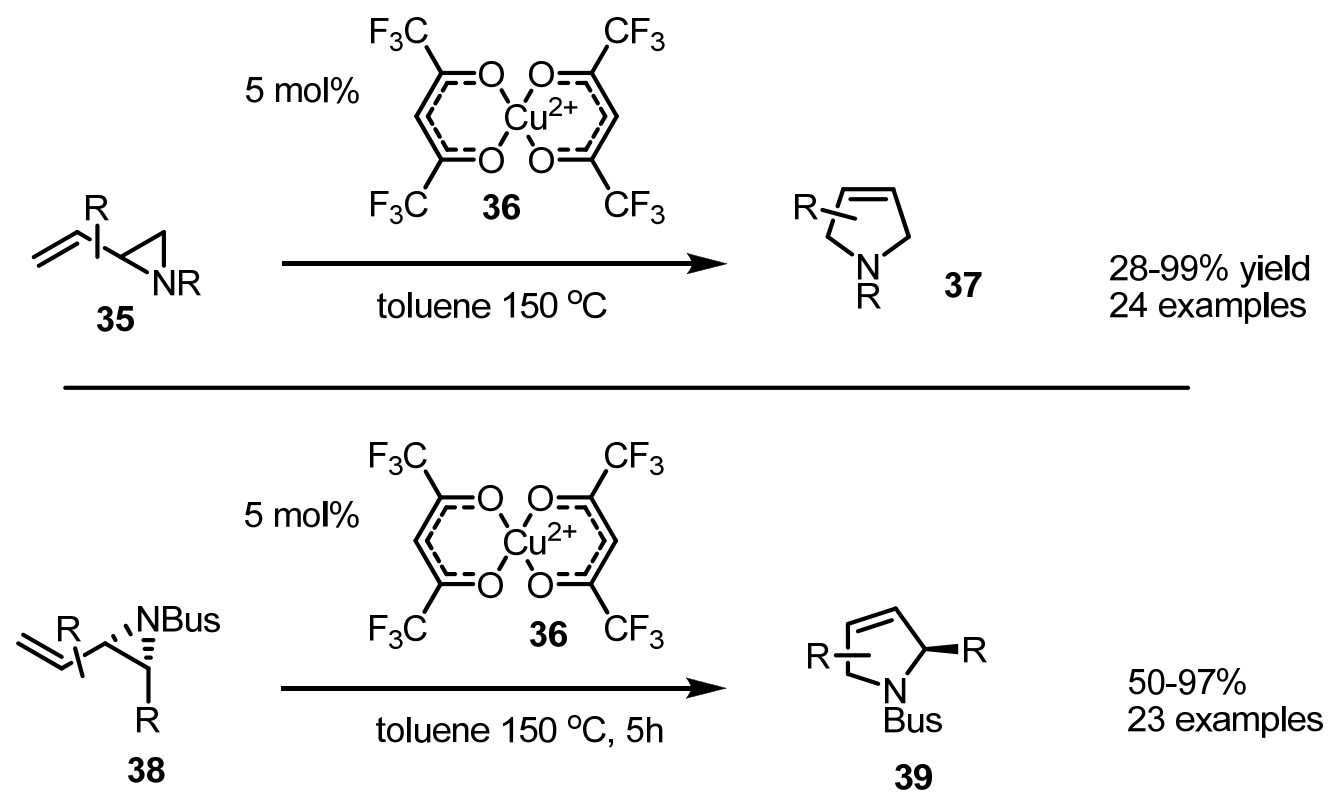

Bus $=$ t-butylsulfonamide

Dual metal catalyzed ring enlargement of vinylaziridines was reported in 2012. The Blum group reported that $\mathrm{Au} / \mathrm{Pd}$ dual catalysis of substituted vinylaziridine $\mathbf{4 0}$ afforded the pyrrolo[1,2a]pyridine $\mathbf{4 1}$ in good yield and diastereoselectivity [17] (Scheme 12). Although the complex catalyst and ligand structure hamper its wide application, this result shows that the combination of metal catalysts and ligands can be optimized in this valuable transformation.

Scheme 12. Dual metal catalysis of vinylaziridines.

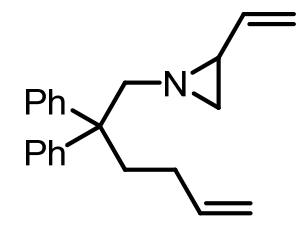

40

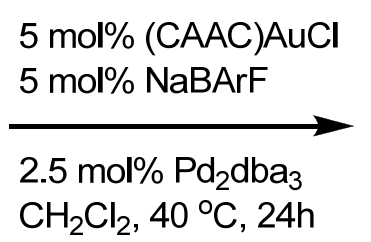

$\mathrm{CH}_{2} \mathrm{Cl}_{2}, 40^{\circ} \mathrm{C}, 24 \mathrm{~h}$
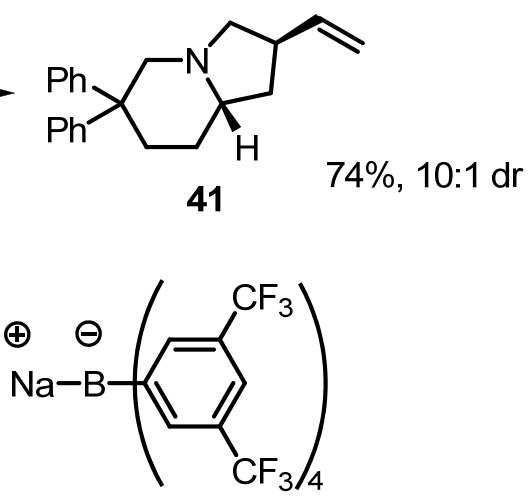

NaBArF

A Pd-catalyzed ring expansion reaction was also utilized recently in the total synthesis of the natural product (-)-chamobtusin A [18] (Scheme 13). The Aoyagi group reported that a $\mathrm{Pd}(0)$-mediated ring opening of vinylaziridine/C-N bond formation/reductive elimination sequence afforded the tricyclic alkaloid 44 in 92\% yield. This synthetic intermediate was then utilized for the total synthesis of 
(-)-chamobtusin A. This result is another good example of the synthetic efficiency of the strain-release reactions of vinylaziridines.

Scheme 13. Total synthesis of (-)-chamobtusin A.

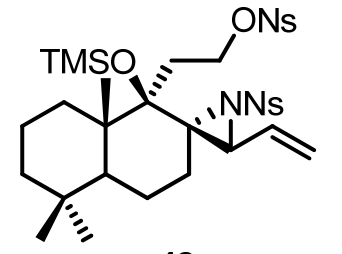

42

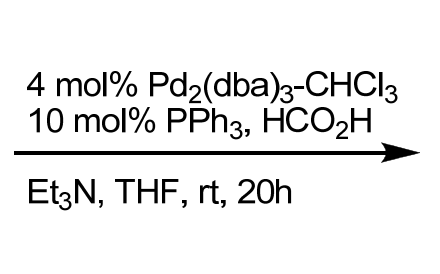<smiles>C=CC[C@]1(N)CC[C@H]2C(C)(C)CCC[C@]2(OS(C)(=O)=O)C1(C)C</smiles>

44

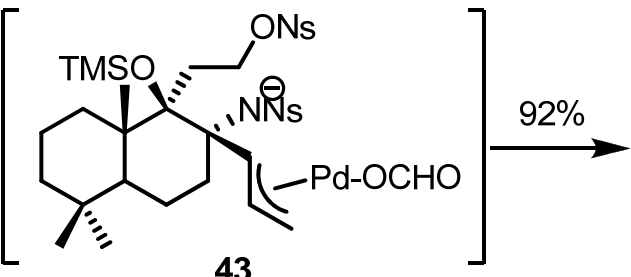

43

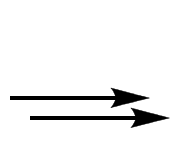

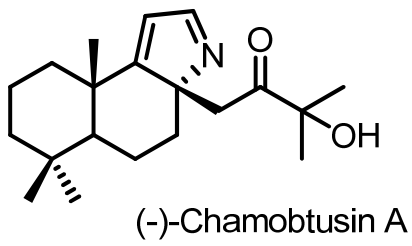

Without metal catalysis, thermal rearrangements of vinylaziridines were also reported [19]. Once the vinylaziridines 45 were heated under microwave, the corresponding pyrrolidine derivatives 46 were produced in high yield, as shown in Scheme 14. Employing this procedure, a formal synthesis of (-)-anisomycin, a natural antibiotic, could be performed. Thermal activation of the substituted vinylaziridine 47 afforded the desired PMB substituted pyrrolidine 48 which could be transformed into (-)-anisomycin by known procedures [20].

Scheme 14. Thermal rearrangement of a vinylaziridine and its application to the synthesis of (-)-anisomycin.

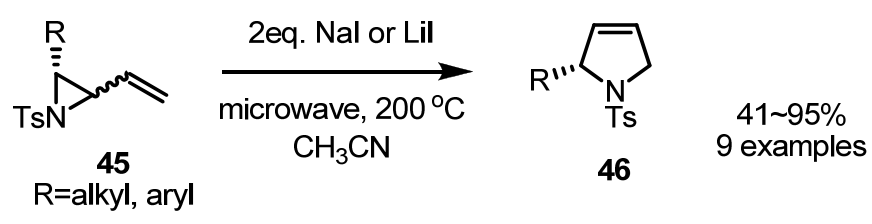<smiles>[C+]#[N+]C1C(C=C)C1Cc1ccc(OC)cc1</smiles>

47

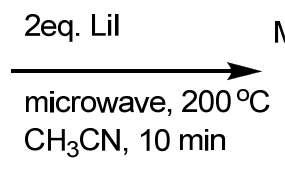

$\mathrm{CH}_{3} \mathrm{CN}, 10 \mathrm{~min}$<smiles>COc1ccc(C[C@@H]2C=CCN2S)cc1</smiles>

48<smiles>COc1ccc(C[C@@H]2NC[C@@H](O)[C@H]2OC2CCCCC2)cc1</smiles>

(-)-anisomycin

More spontaneous rearrangements of vinylaziridine were reported in 2011 [21]. During treatment with vinylmagnesium bromide, the desired transformations from the sulfinylketimines 49 to the corresponding vinylaziridines $\mathbf{5 1}$ were observed in the crude reaction mixture (Scheme 15). The ${ }^{1} \mathrm{H}-\mathrm{HMR}$ analysis showed formation of the desired vinylaziridine derivatives 51 in $33 \%-61 \%, 9 \%-35 \%$ of dehalogenated ketimines $\mathbf{5 0}$ and $19 \%-45 \%$ of the pyrrolidine derivatives $\mathbf{5 2}$ altogether. After purification of the reaction mixture, however, the rearranged pyrrolidine derivatives $\mathbf{5 2}$ were isolated as the exclusive major products. This observation means that spontaneous ring expansions of vinylaziridines can also be performed, depending on their substitution pattern. 
Scheme 15. Spontaneous rearrangement of vinylaziridines to pyrrolidines.

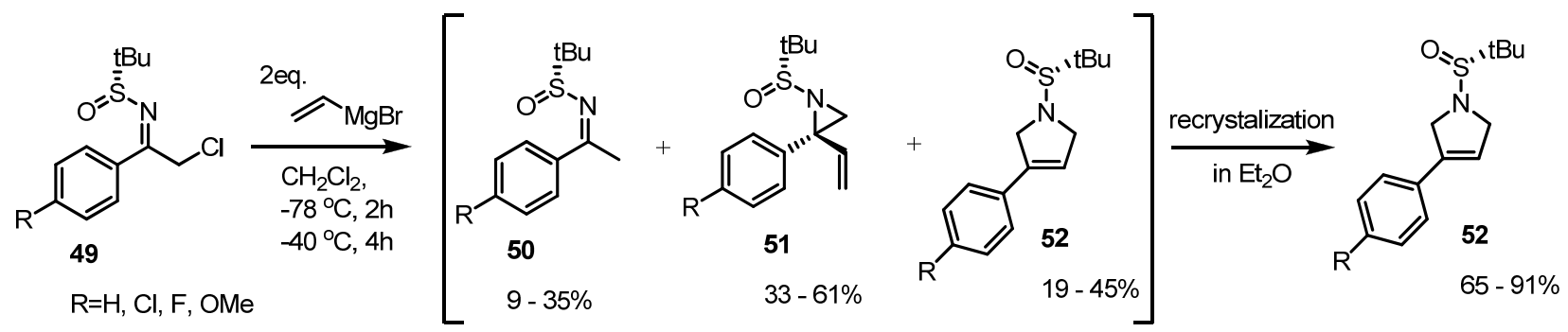

\subsection{Piperidines from Vinylaziridines}

Since the reports of the Coldman group and Somfai group respectively, the [2,3]-rearrangement of vinylaziridines has been regarded as an efficient methodology to prepare 6-membered azacycles [22,23] (Scheme 16).

Scheme 16. Preparation of pyridine derivatives through [2,3]-sigmatropic rearrangement.<smiles>[R]OC(=O)CN1C([R])C1C=CC(=O)N1C([R])C1C(=O)O[R20]</smiles>

Based on the previous result, modification of this conversion was reported in 2004 by the Rowlands group. They had planned that a carbene insertion of diazoacetate into the aziridine would produce an aziridinium ylide $\mathbf{5 4}$ to afford the [2,3]-Stevens rearrangement product $\mathbf{5 5}$ stereoselectively (Equation 6 in Scheme 17) [24]. After extensive survey of reaction conditions, however, this conversion was shown to be hampered by various side reactions or dimerization of metal carbenoid (Equation 7). To avoid this side reaction, instead of intermolecular carbene insertion, intramolecular insertion as shown in Equation 8 was used. When a copper catalyst was added and the reaction mixtures heated in acetonitrile, a [3,5] fused zwitterionic intermediate $\mathbf{5 8}$ was formed and converted to desired pyrrolo[1,2a]pyridine derivative $\mathbf{5 9}$ in low yield. Although this low chemical yield still represents a drawback of this transformation, the well-designed reaction plan and complex framework of the product are expected to be utilized for more developments and applications.

\subsection{Azepines from Vinylaziridines}

Just as a [2,3]-rearrangement of vinylaziridines produces 6-membered azacycles, a [3,3]-rearrangement affords 7-membered azacycles, i.e., azepine skeletons (Scheme 18). It should be noted that this type of ring expansion for vinyl aziridine was historically the first such reaction to be reported $[2,3]$ (Equations 9 and 10 in Scheme 18). So far, many variations or applications of this conversion have been published because it can readily produce generally otherwise unavailable azepine skeletons in a stereoselective manner. 
Scheme 17. Preparation of pyridine derivatives through [2,3]-sigmatropic rearrangement.
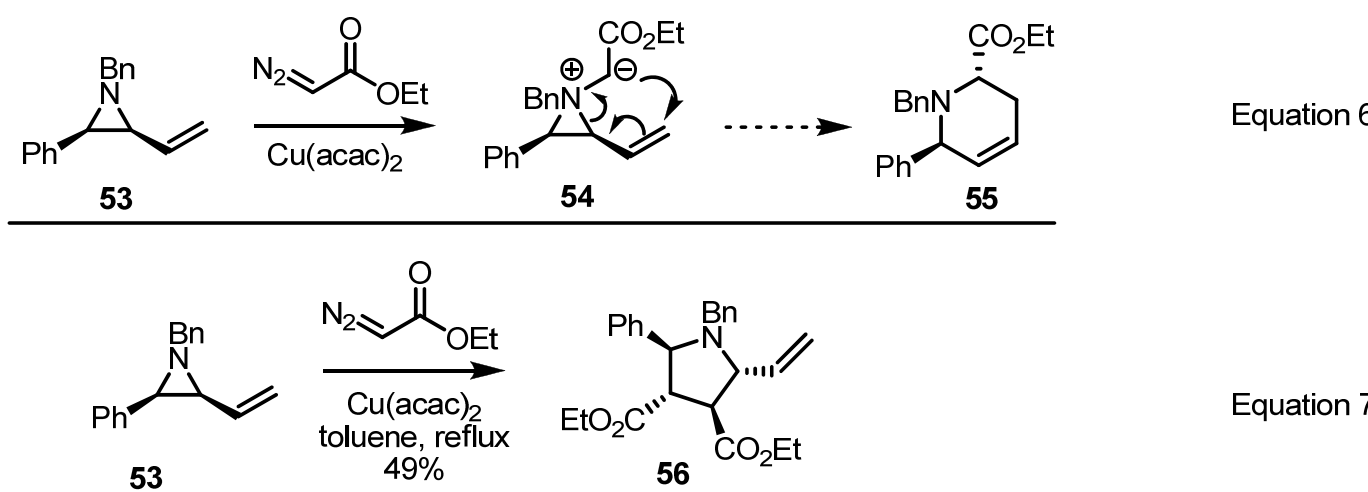

Equation 7

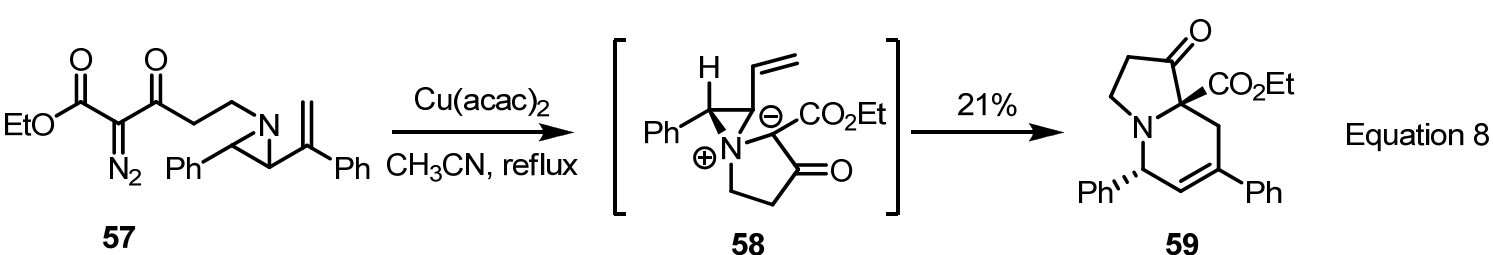

Scheme 18. [3,3]-Sigmatropic rearrangement of vinylaziridines.

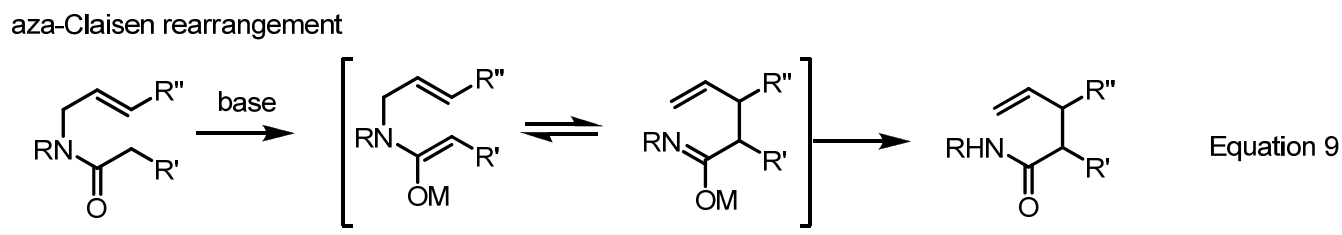

aza-Claisen rearrangement of aziridine amide

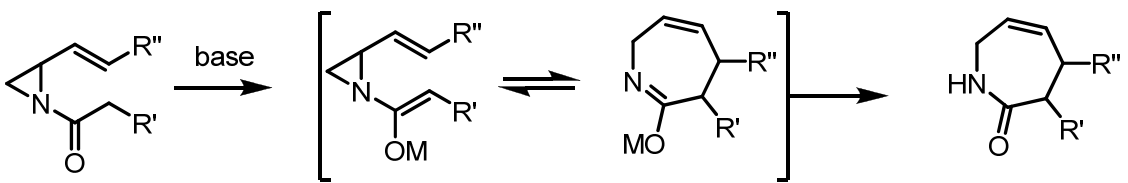

Equation 10

For example, the Somfai group showed a successful synthesis of the substituted azepine 63 using this rearrangement [25]. Because this transformation is a strain-release reaction, the product $\mathbf{6 3}$ is thought to be kinetically favored (Scheme 19).

Scheme 19. Aza-Claisen rearrangement of vinylaziridines.

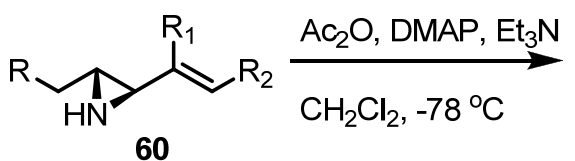

$\mathrm{R}=\mathrm{H}, \mathrm{OBn}, \mathrm{Bn}$<smiles>[R]C=C([R])C1[C@H](C[R])N1C(=O)C[R3]</smiles>

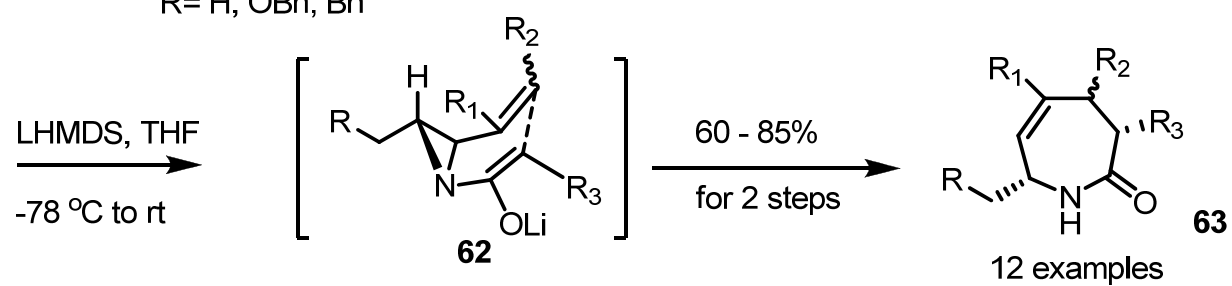


More dramatic application of this conversion to natural product synthesis was achieved by the late Prof. Gin in 2007 [26]. For a total synthesis of cephalotaxine and related natural products, this sigmatropic rearrangement of the substituted vinylaziridine 64 was carried out and found to produce the desired benzazepine $\mathbf{6 5}$ in moderate yield with just the aid of cesium carbonate in 1,4-dioxane solution (Equation 11 in Scheme 20). Employing this protocol, application to the chirally substituted vinylaziridine 66 was examined. As expected, smooth conversion to the desired benzazepine 67 without loss of chirality was observed. With this efficient skeleton preparation method, a successful synthesis of cephalotaxine and the related natural product (-)-deoxyharringtonine, a potent a nti-leukemia alkaloid, could be completed (Equation 12 in Scheme 20).

Scheme 20. Total synthesis of cephalotaxine and deoxyharringtonine.
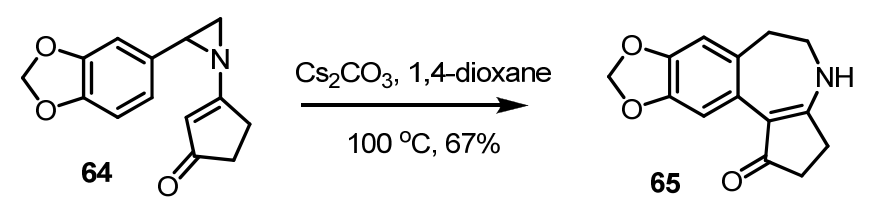

Equation 11
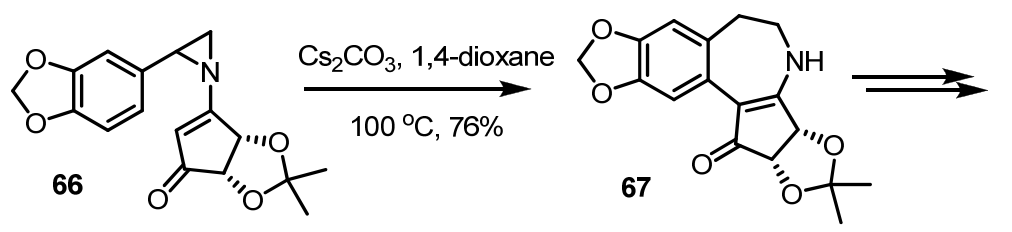

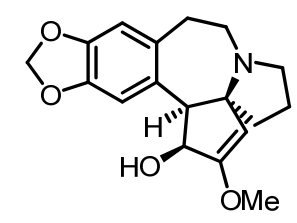

cephalotaxine

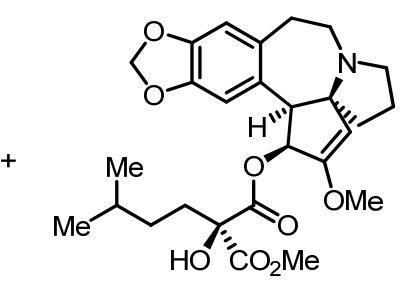

(-)-deoxyharringtonine

A metal catalyzed version of this type of transformation has also been studied. The Gallo group reported a similar conversion using a ruthenium catalyst as shown in Scheme 21 [27].

Scheme 21. Ruthenium catalyzed aza-Claisen rearrangement.<smiles>Nc1ccc([N+](=O)[O-])cc1</smiles>

68

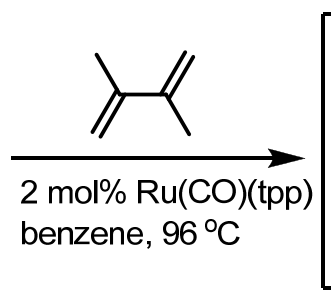<smiles>C=C(C)C1(C)CN1c1ccc([N+](=O)[O-])cc1</smiles>

69<smiles>CC1=C(C)Cc2cc([N+](=O)[O-])ccc2NC1</smiles>

70

Thermal activation of aromatic azide 68 produced an aryl-nitrene to afford a vinylaziridine 69 via nitrene insertion into the alkene moiety. This corresponding vinylaziridine was transformed into the desired benzazepine product $\mathbf{7 0}$ in good yield.

Nickel catalyzed rearrangement of the aziridinylenynes $\mathbf{7 1}$ could also be performed with the $N$-heterocyclic carbene ligand, SIPr [28] (Scheme 22). Ether-tethered vinylaziridine and alkyne cyclize to a mixture of furo[3,4d]azepines $\mathbf{7 2}$ and $\mathbf{7 3}$ in good conversion. It is interesting that phosphine 
ligands gave no conversion of the substrate. Although this reaction still needs more development in terms of chemical yield and substrate scope, it has room for application of chiral catalysts and ligands.

Scheme 22. NHC-assisted rearrangement of the vinylaziridine $\mathbf{7 1 .}$<smiles>CC#CCOC/C=C/C1CN1</smiles>

71

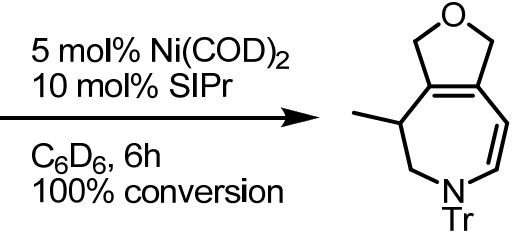

72<smiles>CC1=C2COCC2C=CN([I+])C1</smiles>

73<smiles>Cc1c(C(C)C)cccc1C(C)N1CCN(c2c(C(C)C)cccc2C(C)C)C1(C)C</smiles>

SIPr

$4: 1$

Independently of the sigmatropic rearrangement, a cycloaddition of isocyanates with vinylaziridines was also executed. When tosyl isocyanate was added to the benzyl vinylaziridine $\mathbf{7 4}$, the azepine $\mathbf{7 5}$ was obtained in good yield (Scheme 23). It should be noted that choice of solvent can influence the regioselectivity of this conversion [29]. Thus, with DMF as solvent, imidazole derivative 76 was produced as the major isomer, albeit in low chemical yield. When DMF was replaced by $\mathrm{CH}_{2} \mathrm{Cl}_{2}$ as solvent, the desired azepine derivatives were produced in good chemical yield and regioselectivity. After an extensive optimization of the reaction conditions, the vinylaziridine $\mathbf{7 7}$ could be converted into the urea $\mathbf{7 8}$ in $90 \%$ yield.

Scheme 23. Cycloaddition of isocyanates to form azepine derivatives.

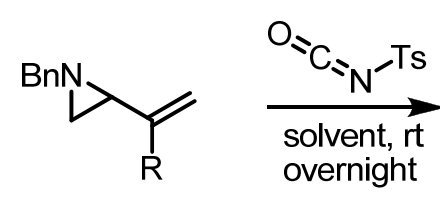

74<smiles>[R]C1=CCNC(=O)[NH2+]C1</smiles>

75<smiles>[R]C(=C)C1CNC(=O)[NH2+]1</smiles>

$\begin{array}{lll}\mathrm{DMF} ; 28 \% & <5 & >95 \\ \mathrm{CH}_{2} \mathrm{Cl}_{2} ; 64 \% & >95 & <5\end{array}$

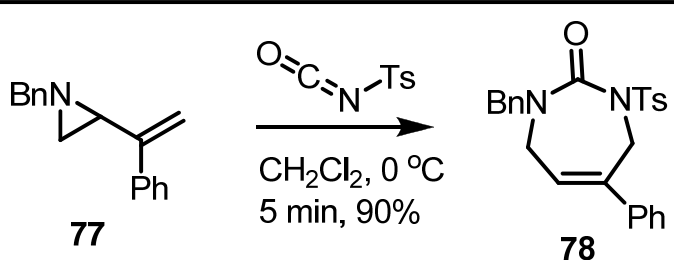

\section{Conclusions}

Recent advances in the strain-release ring enlargement of the vinylaziridine moiety were described. Owing to their unique reactivity, vinylaziridines are still regarded as attractive synthetic intermediates, as summarized above. Their further variations, improvements and applications will be a highly active research topic because the reaction still has unmet needs in terms of regio- and stereoselectivity. With this synthetic endeavor, it can be expected that more fruitful results will be realized, just as they were in the last decade. 


\section{Acknowledgments}

This work was supported by the Basic Science Research Program through the National Research Foundation of Korea (NRF) funded by the Ministry of Education, Science and Technology (NRF-2011-0007845). This work was also supported by a grant from the Next-Generation BioGreen 21 Program (SSAC, no. PJ0090882013).

\section{Conflict of Interest}

The authors declare no conflict of interest.

\section{References}

1. Cardoso, A.L.; Pinho e Melo, T.M.V.D. Aziridines in formal [3+2] cycloadditions: Synthesis of five-membered heterocycles. Eur. J. Org. Chem. 2012, 33, 6479-6501.

2. Scheiner, P. Rearrangements of a 2-vinylaziridine. J. Org. Chem. 1967, 32, 2628-2630.

3. Stogryn, E.L.; Brois, S.J. The valence isomerization of 1,2-divinylaziridines. Synthetic and kinetic studies. J. Am. Chem. Soc. 1967, 89, 605-609.

4. Tanner, D.; Somfai, P. Palladium-catalyzed transformation of a chiral vinylaziridine to a $\beta$-lactam. An enantioselective route to the carbapenem (+)-PS-5. Bioorg. Med. Chem. Lett. 1993, 3, 2415-2418.

5. Aggarwal, V.K.; Alonso, E.; Fang, G.; Ferrara, M.; Hynd, G.; Porcelloni, M. Application of chiral sulfides to catalytic asymmetric aziridination and cyclopropanation with in situ generation of the diazo compound. Angew. Chem. Int. Ed. Engl. 2001, 40, 1433-1436.

6. Fontana, F.; Tron, G.C.; Barbero, N.; Ferrini, S.; Thomas, S.P.; Aggarwal, V.K. Stereoselective synthesis of trans-beta-lactams by palladium-catalysed carbonylation of vinylaziridines. Chem. Commun. 2010, 46, 267-269.

7. Branchadell, V.; Moreno-Mañas, M.; Pleixats, R. Theoretical study on the regioselectivity of nucleophilic attack in silyl-substituted (diphosphino)( $\eta 3$-allyl) palladium cations. Organometallics 2002, 21, 2407-2412.

8. Butler, D.C.; Inman, G.A.; Alper, H. Room temperature ring-opening cyclization reactions of 2-vinylaziridines with isocyanates, carbodiimides, and isothiocyanates catalyzed by [Pd(OAc)2]/PPh3. J. Org. Chem. 2000, 65, 5887-5890.

9. Trost, B.M.; Fandrick, D.R. Dynamic kinetic asymmetric cycloadditions of isocyanates to vinylaziridines. J. Am. Chem. Soc. 2003, 125, 11836-11837.

10. Fontana, F.; Chen, C.C.; Aggarwal, V.K. Palladium-catalyzed insertion of $\mathrm{CO}_{2}$ into vinylaziridines: New route to 5-vinyloxazolidinones. Org. Lett. 2011, 13, 3454-3457.

11. Aoyagi, K.; Nakamura, H.; Yamamoto, Y. Palladium-catalyzed aminoallylation of activated olefins with allylic halides and phthalimide. J. Org. Chem. 2002, 67, 5977-5980.

12. Lowe, M.A.; Ostovar, M.; Ferrini, S.; Chen, C.C.; Lawrence, P.G.; Fontana, F.; Calabrese, A.A.; Aggarwal, V.K. Palladium-mediated annulation of vinylaziridines with michael acceptors: Stereocontrolled synthesis of substituted pyrrolidines and its application in a formal synthesis of (-)- $\alpha$-kainic acid. Angew. Chem. Int. Ed. Engl. 2011, 123, 6494-6498.

13. Baktharaman, S.; Afagh, N.; Vandersteen, A.; Yudin, A.K. Unprotected vinylaziridines: Facile synthesis and cascade transformations. Org. Lett. 2010, 12, 240-243. 
14. Brichacek, M.; Lee, D.; Njardarson, J.T. Lewis Acid catalyzed [1,3]-sigmatropic rearrangement of vinylaziridines. Org. Lett. 2008, 10, 5023-5026.

15. Mack, D.J.; Njardarson, J.T. New Mechanistic insights into the copper catalyzed ring expansion of vinylaziridines: Evidence in support of a copper(I) mediated pathway. Chem. Sci. 2012, 3, 3321-3325.

16. Brichacek, M.; Navarro Villalobos, M.; Plichta, A.; Njardarson, J.T. Stereospecific ring expansion of chiral vinylaziridines. Org. Lett. 2011, 13, 1110-1113.

17. Hirner, J.J.; Roth, K.E.; Shi, Y.; Blum, S.A. Mechanistic Studies of azaphilic versus carbophilic activation by gold (I) in the gold/palladium dual-catalyzed rearrangement of alkenyl vinylaziridines. Organometallics 2012, 31, 6843-6850.

18. Suzuki, H.; Aoyagi, S. Total Synthesis of (-)-Chamobtusin A. Org. Lett. 2012, 14, 6374-6376.

19. Hirner, S.; Somfai, P. Microwave-assisted rearrangement of vinylaziridines to 3-pyrrolines: Formal synthesis of (-)-anisomycin. Synlett 2005, 20, 3099-3102.

20. Buchanan, J.G.; MacLean, K.A.; Wightman, R.H.; Paulsen, H. A new synthesis of (-)-anisomycin and its demethoxy analogue from D-ribose. J. Chem. Soc. Perkin Trans. 1 1985, 1463-1470.

21. Leemans, E.; Colpaert, F.; Mangelinckx, S.; de Brabandere, S.; Denolf, B.; de Kimpe, N. Synthesis of 3-aryl-3-pyrrolines and 3-arylpyrroles via spontaneous rearrangement of $N$-sulfinyl 2-aryl-2-vinylaziridines Synlett 2011, 5, 674-678.

22. Coldham, I.; Collis, A.J.; Mould, R.J.; Rathmell, R.E. Ring expansion of aziridines to piperidines using the aza-wittig rearrangement. Tetrahedron Lett. 1995, 36, 3557-3560.

23. Ahman, J.; Somfai, P. Enantioselective total synthesis of (-)-indolizidines 209B and 209D via a highly efficient aza-[2,3]-wittig rearrangement of vinylaziridines. Tetrahedron 1995, 51, 9747-9756.

24. Rowlands, G.J.; Barnes, W.K. Studies on the [2,3]-Stevens rearrangement of aziridinium ions. Tetrahedron Lett. 2004, 45, 5347-5350.

25. Lindström, U.M.; Somfai, P. Aza-[3,3]-claisen enolate rearrangement in vinylaziridines: Stereoselective synthesis of mono-, di-, and trisubstituted seven-membered lactams. Chem. Eur. J. 2001, 7, 94-98.

26. Eckelbarger, J.D.; Wilmot, J.T.; Gin, D.Y. Strain-release rearrangement of $N$-vinyl-2-arylaziridines. Total synthesis of the anti-leukemia alkaloid (-)-deoxyharringtonine. J. Am. Chem. Soc. 2006, 128, 10370-10371.

27. Fantauzzi, S.; Gallo, E.; Caselli, A.; Piangiolino, C.; Ragaini, F.; Re, N.; Cenini, S. Rearrangement of $\mathrm{N}$-aryl-2-vinylaziridines to benzoazepines and dihydropyrroles: A synthetic and theoretical study. Chem. Eur. J. 2009, 15, 1241-1251.

28. Zuo, G.; Zhang, K.; Louie, J. Nickel-catalyzed reactions of vinylaziridines and aziridinylen-ynes. Tetrahedron Lett. 2008, 49, 6797-6799.

29. Kanno, E.; Yamanoi, K.; Koya, S.; Azumaya, I.; Masu, H.; Yamasaki, R.; Saito, S. [5+2] Cycloaddition reaction of 2-vinylaziridines and sulfonyl isocyanates. Synthesis of seven-membered cyclic ureas. J. Org. Chem. 2012, 77, 2142-2148.

Sample Availability: Not availability.

(C) 2013 by the authors; licensee MDPI, Basel, Switzerland. This article is an open access article distributed under the terms and conditions of the Creative Commons Attribution license (http://creativecommons.org/licenses/by/3.0/). 